\title{
Papers
}

\section{House dust mite control measures in the management of asthma: meta-analysis}

Peter C Gøtzsche, Cecilia Hammarquist, Michael Burr

\begin{abstract}
Objective To determine whether patients with asthma who are sensitive to mites benefit from measures designed to reduce their exposure to house dust mite antigen in the home.

Design Meta-analysis of randomised trials that investigated the effects on asthma patients of chemical or physical measures to control mites, or both, in comparison with an untreated control group. All trials in any language were eligible for inclusion.

Subjects Patients with bronchial asthma as diagnosed by a doctor and sensitisation to mites as determined by skin prick testing, bronchial provocation testing, or serum assays for specific IgE antibodies.

Main outcome measures Number of patients whose allergic symptoms improved, improvement in asthma symptoms, improvement in peak expiratory flow rate. Outcomes measured on different scales were combined using the standardised effect size method (the difference in effect was divided by the standard deviation of the measurements).

Results 23 studies were included in the meta-analysis; 6 studies used chemical methods to reduce exposure to mites, 13 used physical methods, and 4 used a combination. Altogether, 41/113 patients exposed to treatment interventions improved compared with $38 / 117$ in the control groups (odds ratio 1.20, 95\% confidence interval 0.66 to 2.18). The standardised mean difference for improvement in asthma symptoms was -0.06 (95\% confidence interval -0.54 to 0.41$)$. For peak flow rate measured in the morning the standardised mean difference was $-0.03(-0.25$ to $0.19)$. As measured in the original units this difference between the treatment and the control group corresponds to $-3 \mathrm{l} / \mathrm{min}(95 \%$ confidence interval $-25 \mathrm{l} / \mathrm{min}$ to $19 \mathrm{l} / \mathrm{min}$ ). The results were similar in the subgroups of trials that reported successful reduction in exposure to mites or had long follow up times.

Conclusion Current chemical and physical methods aimed at reducing exposure to allergens from house dust mites seem to be ineffective and cannot be recommended as prophylactic treatment for asthma patients sensitive to mites.
\end{abstract}

\section{Introduction}

The major allergen in house dust is derived from mites, and a recent review concluded that the environmental control of allergens should be an integral part of the management of sensitised patients. ${ }^{1}$ Some of the evidence in the review, however, was derived from observational studies. Since clinical trials have shown equivocal results of the effectiveness of measures to reduce exposure to mite antigen, we decided to synthesise the findings of all clinical trials.

\section{Methods}

Our objective was to determine whether patients with asthma who were sensitised to house dust mites benefited from measures designed to reduce their exposure to mite antigen in the home. All randomised trials in any language performed at any time that compared chemical (acaricidal) or physical measures (such as vacuum cleaning, heating, barrier methods, or air filtration systems) to control mites and analysed their effects on patients with bronchial asthma as compared with an untreated control group were eligible for inclusion in the meta-analysis. Asthma had to have been diagnosed by a doctor and sensitisation to mites had to have been assessed by skin tests, bronchial provocation tests, or serum assays for specific IgE antibodies.

\section{Search strategy}

We searched the Asthma and Wheez* databases set up by the Cochrane Airways Group which contain records from the Cumulative Index to Nursing and Allied Health Literature, Medline, and Embase. Mite* in the title, abstract, or keyword (descriptor) field was combined with random*, trial*, placebo, double-blind, double blind, single-blind, single blind, comparative study, or controlled study in all fields. Primary authors were contacted to obtain additional information if necessary. CH searched issues of Respiration (1980-96) and MB searched Clinical and Experimental Allergy (198096) by hand.

\section{Extraction of data}

Two of the authors (CH and $\mathrm{MB}$ ) selected the trials for inclusion. Two (PCG and $\mathrm{CH}$ ) extracted data on the following outcomes: subjective wellbeing, improvement in asthma symptoms, use of drugs to control asthma, number of days of sick leave taken from school or work, number of unscheduled visits made to a doctor or hospital, forced expiratory volume in 1 second,
Editorial by Strachan

Nordic Cochrane Centre,

Rigshospitalet,

Department 7112, DK-2200 Copenhagen N, Denmark

Peter C Gøtzsche director

Executive Office, Unit of Public Health, Municipality of Gotland, S-62181

Visby, Sweden

Cecilia

Hammarquist,

director

Centre for Applied

Public Health

Medicine,

University of Wales

College of

Medicine, Cardiff

CF1 3NW

Michael Burr,

consultant

Correspondence to:

Dr Gøtzsche

p.c.gotzsche@

cochrane.dk

BMJ 1998;317:1105-10

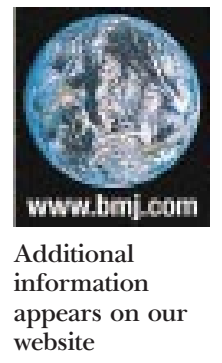


Characteristics of the 23 studies included in the meta-analysis of methods to control exposure to mites among asthma patients

\begin{tabular}{|c|c|c|c|c|c|c|c|}
\hline Study (year) & $\begin{array}{c}\text { Type of } \\
\text { intervention }\end{array}$ & Design & $\begin{array}{c}\text { Mean age } \\
\text { or age } \\
\text { range of } \\
\text { patients } \\
\text { (years) }\end{array}$ & $\begin{array}{l}\text { No of } \\
\text { patients in } \\
\text { study }\end{array}$ & $\begin{array}{c}\text { No of } \\
\text { patients not } \\
\text { completing } \\
\text { study }\end{array}$ & $\begin{array}{l}\text { Length of } \\
\text { follow up }\end{array}$ & $\begin{array}{c}\text { Reduction in } \\
\text { exposure to } \\
\text { mites or mite } \\
\text { antigen } \\
\text { achieved }\end{array}$ \\
\hline Dietemann et al $(1993)^{9}$ & Chemical & Parallel trial, double blind & 36 & 26 & 3 & 1 year & No \\
\hline Ehnert et al $(1992)^{11}$ & Chemical & Parallel trial, double blind & 10 & 16 & 0 & 1 year & No \\
\hline Geller-Bernstein et al $(1995)^{12}$ & Chemical & Parallel trial, double blind & 9 & 35 & 3 & 6 months & No \\
\hline Van der Heide et al $(1997)^{24}$ & Chemical & Parallel trial, double blind & 31 & 40 & 0 & 1 year & No \\
\hline Reiser et al $(1990)^{16}$ & Chemical & Parallel trial, double blind & $5-16$ & 51 & 5 & 3 months & No \\
\hline Sette et al $(1994)^{17}$ & Chemical & Parallel trial, double blind & 13 & 24 & 0 & 2 weeks & No \\
\hline Antonicelli et al $(1991)^{5}$ & Physical & Crossover trial, assessor blind & 16 & 9 & 0 & 8 weeks & No \\
\hline Burr et al $(1976)^{6}$ & Physical & Crossover trial, no blinding & 33 & 32 & 0 & 6 weeks & NA \\
\hline Burr et al $(1980)^{7}$ & Physical & Parallel trial, double blind & 9 & 55 & 2 & 8 weeks & No \\
\hline Burr et al $(1980)^{8}$ & Physical & Crossover trial, no blinding & 9 & 21 & 0 & 1 month & No \\
\hline Gillies et al $(1987)^{13}$ & Physical & Parallel trial, no blinding & 10 & 26 & 1 & 6 weeks & No \\
\hline Huss et al $(1992)^{25}$ & Physical & Parallel trial, no blinding & 44 & 52 & 0 & 12 weeks & Yes \\
\hline Maesen et al $(1977)^{26}$ & Physical & Crossover trial, double blind & $7-55$ & 30 & 2 & 1 month & NA \\
\hline Mitchell and Elliott $(1980)^{15}$ & Physical & Crossover trial, no blinding & 10 & 10 & 0 & 4 weeks & NA \\
\hline Verrall et al $(1988)^{18}$ & Physical & Crossover trial, double blind & 14 & 16 & 3 & 3 weeks & NA \\
\hline Walshaw and Evans (1986) ${ }^{19}$ & Physical & Parallel trial, no blinding & 34 & 50 & 8 & 1 year & Yes \\
\hline Warburton et al $(1994)^{20}$ & Physical & Crossover trial, double blind & 46 & 13 & 1 & 4 weeks & No \\
\hline Warner et al $(1993)^{21}$ & Physical & Crossover trial, double blind & 9 & 20 & 6 & 6 weeks & Yes \\
\hline Zwemer and Karibo $(1973)^{22}$ & Physical & Crossover trial, double blind & $6-16$ & 18 & 6 & 4 weeks & NA \\
\hline Carswell et al $(1996)^{23}$ & Combination & Parallel trial, double blind & 10 & 70 & 21 & 24 weeks & Yes \\
\hline Dorward et al $(1988)^{10}$ & Combination & Parallel trial, assessor blind & 25 & 21 & 3 & 8 weeks & Yes \\
\hline Ehnert et al (1992) ${ }^{11}$ & Combination & Parallel trial, no blinding & 10 & 16 & 0 & 1 year & Yes \\
\hline Marks et al $(1994)^{14}$ & Combination & Parallel trial, participants blind & 35 & 35 & 5 & 6 months & No \\
\hline
\end{tabular}

NA=not assessed.

peak expiratory flow rate, provocative concentration that causes a $20 \%$ fall in forced expiratory volume in 1 second, and results of skin prick testing. Ambiguities were resolved by discussion.

\section{Statistical methods}

Review Manager software was used to analyse the data. ${ }^{2}$ If $\mathrm{P}<0.10$ in the test for heterogeneity a random effects analysis was carried out. Since the results from crossover trials were usually reported as if they had come from a parallel group trial we used the data accordingly and assumed that no carryover effect had occurred. Continuous data were often presented on different scales in different studies (for example, peak expiratory flow rate was given either as absolute values or as a per cent of predicted values). Because of this, we calculated the standardised mean difference in our analysis of these data. With this method, the difference in effect is divided by the standard deviation of the measurements. Since data on wellbeing and improvements in asthma symptoms were closely related we summarised categorical data as the number of patients whose asthma improved; we summarised continuous data in the category of asthma symptoms. In general, the provocative concentration that causes a $20 \%$ fall in the forced expiratory volume in 1 second had been analysed after logarithmic transformation because the data were highly skewed. If the mean values and standard deviations had been converted from the logarithmic to the arithmetic scale we reconverted them. ${ }^{3}$ We excluded data on the provocative concentration from one study which had not used logarithmic transformation (see appendix 1 on the website).

In studies in which the use of several anti-asthma treatments had been reported we used the data on bronchodilators. In studies in which data were recorded at several points in time we used the longest observation period during which patients were still on randomised treatment.

We did not adjust for baseline differences since inequalities occurring despite randomisation would be expected to cancel each other out over a number of trials. Furthermore, baseline values were not always available. If we had made adjustments when possible we would have risked biasing the review since investigators may be inclined to show baseline differences and adjust for them when this procedure favours the experimental treatment. Bias occurring during the analysis of data is common and almost always favours the new treatment. ${ }^{4}$

\section{Results}

Trials included in the analysis

Altogether, 458 references were identified; half of these were irrelevant and the other half were retrieved so that the full study could be examined. Eighteen of the 229 studies met the inclusion criteria. ${ }^{5-22}$ Another four trials were retrieved from MB's personal archive. ${ }^{23-26}$ The reference lists of the 229 articles retrieved were also searched but no further appropriate studies were found. One of the papers included in the analysis ${ }^{11}$ reported on a trial with three arms; this was treated as two separate trials in the meta-analysis. Thus, most of the analyses below refer to 23 trials. (A list of the excluded trials which were not evidently irrelevant and the reasons for their exclusion appear in appendix 2 on the website.)

All studies had used skin prick testing for diagnosis of mite sensitisation. Extracts were from Dermatophagoides pteronyssinus or $D$ farinae except in two trials which had used an unspecified extract of house dust. $^{22}{ }^{26}$ Two trials also used a serum assay for specific IgE antibodies. ${ }^{911}$ Patients had mostly been recruited 
from asthma and chest clinics. The specific criteria for the diagnosis of asthma were mentioned only in four papers. $^{11} 141725$

Six studies used chemical methods to reduce exposure to mites, ${ }^{91112161724} 13$ used physical methods, ${ }^{5-8} 131518-222526$ and four used a combination of methods. ${ }^{1111423}$ Five studies did not assess the reduction of the population of mites. ${ }^{6} 151822{ }^{26}$ Reduction in the exposure to mites occurred in six studies $^{1011} 19212325$; reduction was unsuccessful in 12. ${ }^{5-9} 11-1416172024$ The length of follow up, from two weeks to one year, and other characteristics of the studies are shown in the table.

Only one study reported enough information to allow us to determine that allocation had been adequately concealed ${ }^{12}$; in the remaining articles authors stated that the study was randomised. Thirteen of the studies were double blind or placebo controlled with blind assessment; two studies used blinded assessors and one had blinded participants; nine were crossover studies (table). Altogether, 686 patients were enrolled in the studies.

\section{Results of meta-analysis}

The total number of patients who improved after intervention was similar to the total number who improved among the control groups (41/113 in treatment group $v 38 / 117$ in control group, odds ratio 1.20 , $95 \%$ confidence interval 0.66 to 2.18 ) (fig 1 ). Improvements in asthma symptoms were heterogeneous $(\mathrm{P}<0.0001)$ but there was no indication of an effect. The standardised mean difference of these scores was -0.06 (95\% confidence interval -0.54 to 0.41$)$ (fig 2). The result was similar when analysis was done with a fixed effects model $(-0.01,-0.28$ to 0.26$)$.

The most commonly reported outcome was peak expiratory flow rate in the morning (fig 3). The time of

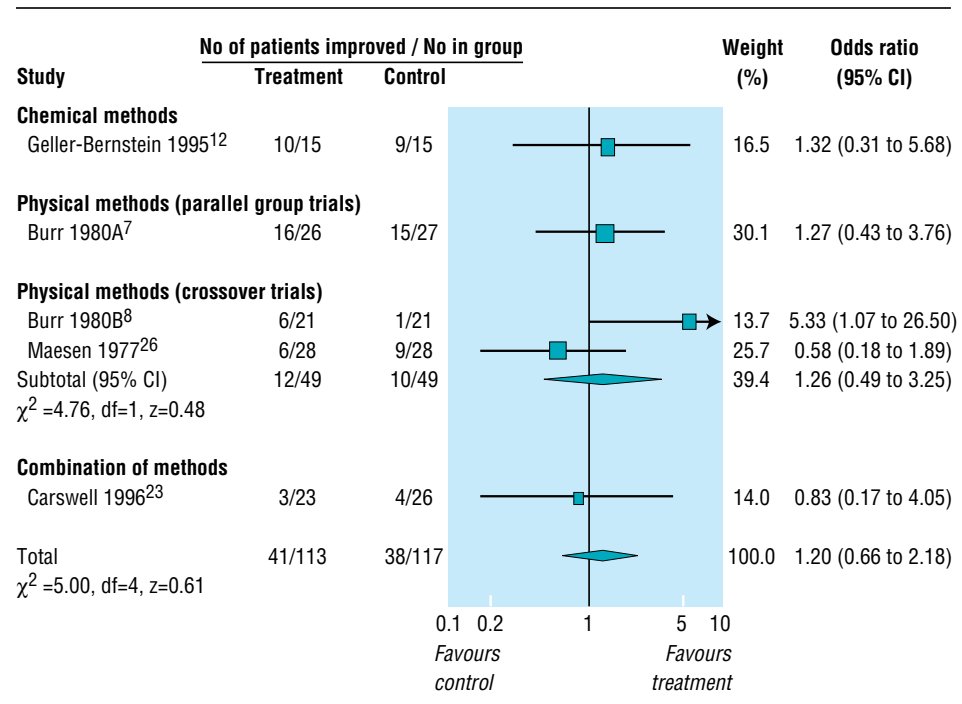

Fig 1 Odds ratios (95\% confidence interval) of number of asthma patients whose symptoms improved after the use of either chemical or physical methods to reduce exposure to house dust mites

day that peak expiratory flow was measured was not stated in one study ${ }^{19}$; we assumed that it had been measured in the morning. The standardised mean difference between peak expiratory flow rates was -0.03 $(-0.25$ to 0.19$)$. In the analysis of chemical methods to reduce the population of house dust mites there was a significant difference between treatment and control groups $(-0.50,-0.98$ to -0.01$)$ which favoured the control group (one of the two studies had a baseline difference which favoured the control group ${ }^{9}$ ). In the analysis of five crossover trials of physical methods the difference was 0.06 ( -0.26 to 0.37 ) (fig 3 ); for the only parallel group trial the difference was $0.33(-0.28$ to

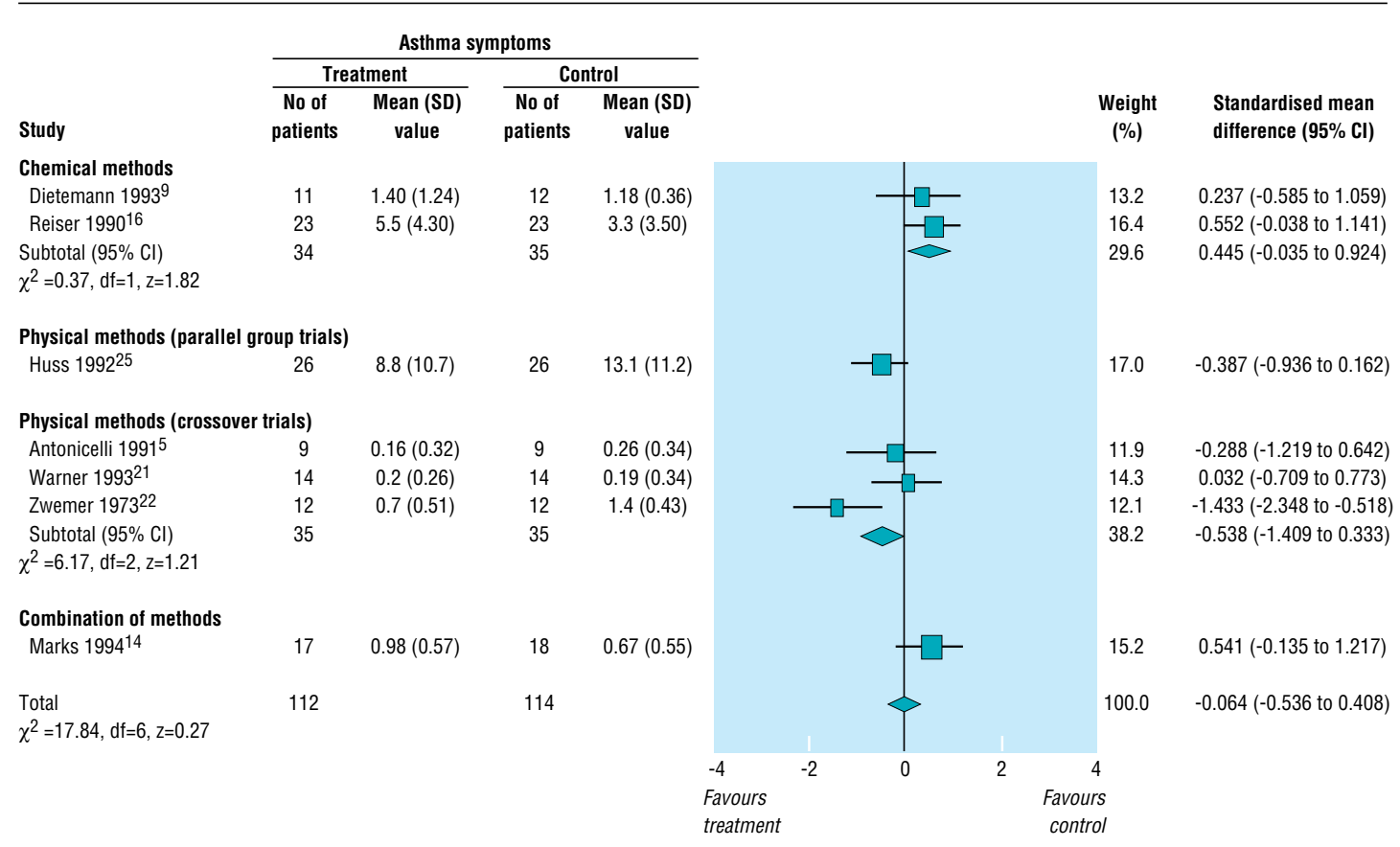

Fig 2 Standardised mean difference (95\% confidence interval) in asthma symptoms after the use of either chemical or physical methods to reduce exposure to house dust mites. Negative values indicate that treatment is better than control 


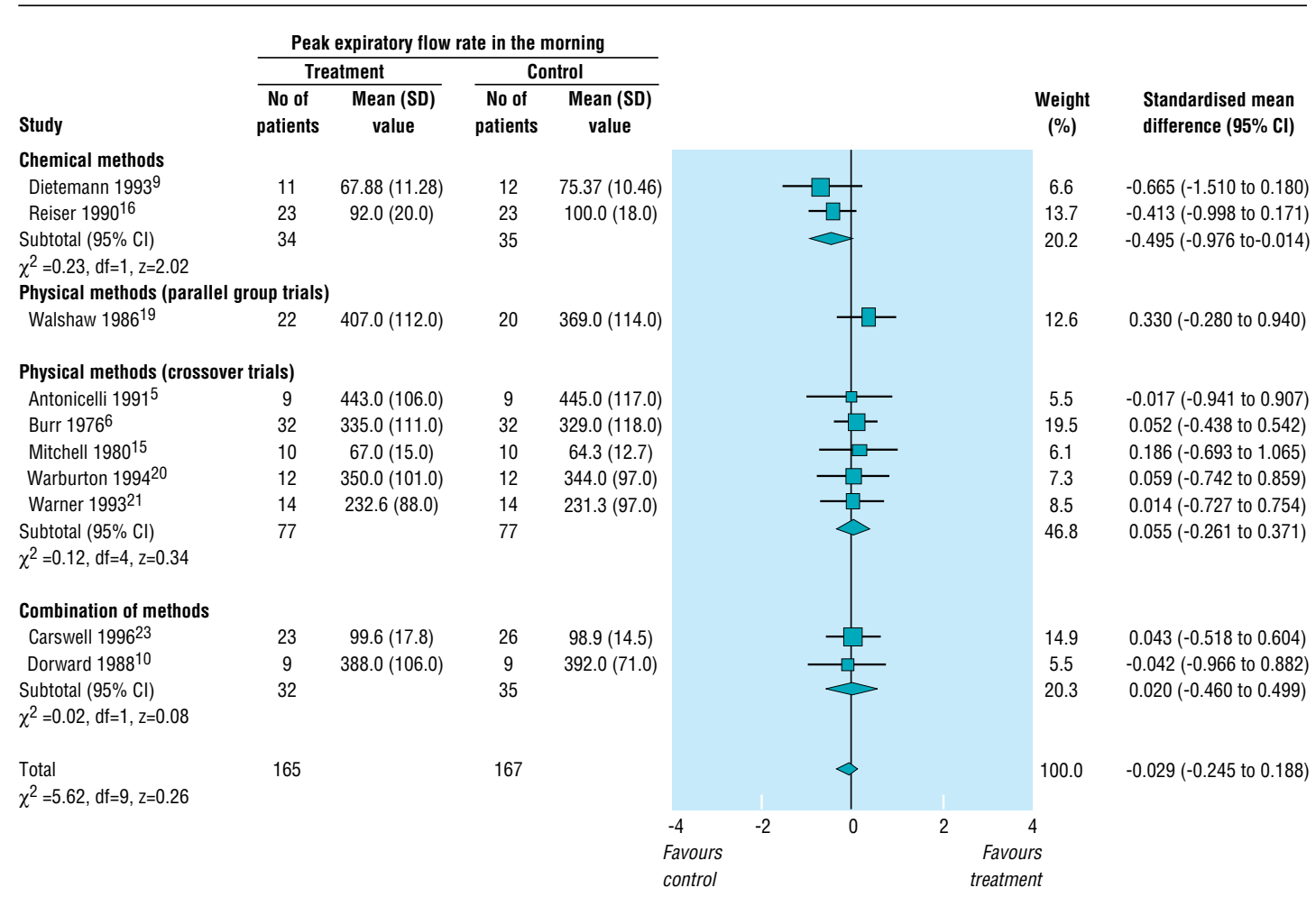

Fig 3 Standardised mean difference (95\% confidence interval) of peak expiratory flow rate in the morning after the use of either chemical or physical methods to reduce exposure to house dust mites. Positive values indicate that treatment is better than control

0.94). ${ }^{19}$ For the two studies evaluating a combination of methods the difference was $0.02(-0.46$ to 0.50$)$.

Peak expiratory flow in the evening was only reported in six trials ${ }^{510152021}$; the difference was -0.13 ( -0.48 to 0.22$)$. For the only study that reported on chemical methods the difference was $-1.08(-1.97$ to -0.20$)$ in favour of the control group. ${ }^{9}$ For physical methods of control the difference was 0.06 ( -0.35 to 0.47 ). For the trials evaluating a combination of methods it was -0.03 ( -0.96 to 0.89 ). The difference for forced expiratory volume in 1 second was $0.09(-0.16$ to 0.33 ).

There was no difference between the treatments in their effects on provocative concentration (standardised mean difference $0.04,-0.32$ to 0.23 ) or use of drugs $(-0.14,-0.43$ to 0.15$)$. Data for chemical methods were given only in one study in which the use of anti-asthma drugs was significantly higher in the treatment group (0.89, 0.02 to 1.75$))^{9}$

None of the studies reported on the number of unscheduled visits made to a doctor or hospital. One study reported that three patients missed school during the control period and none missed school during treatment but did not give reasons for these differences. ${ }^{22}$ Results of skin prick testing after treatment were not reported in any study.

In the subgroup of trials that reported a successful reduction in the population of mites the results were similar to the overall results. ${ }^{1011} 19212325$ For measures of morning peak flow rate the difference was 0.11 $(-0.22$ to 0.45$)$. The only parallel group trial in this subgroup had a baseline difference that favoured the experimental group ${ }^{19}$; if this trial is excluded the difference becomes 0.02 ( -0.39 to 0.42 ).

\section{Discussion}

We were unable to show any clinical benefit from measures designed to reduce exposure to mites among asthma patients who were sensitive to mites. Since patients with asthma are frequently sensitive to house dust mite allergen, the most likely explanation for our negative findings is that the methods studied did not adequately reduce levels of mite antigens. Those few studies in which exposure to mites was effectively reduced did not have results that were more positive than studies in which exposure to mites was not reduced. This may be because patients with asthma who are sensitive to mites are usually also sensitive to other allergens; the successful elimination of only one allergen may be of limited benefit.

It seems unlikely that the initial levels of mite infestation were already too low for any reduction to be effective. Quite low concentrations of allergen can affect bronchial responsiveness, ${ }^{27}{ }^{28}$ and the concentrations in the studies reviewed would usually represent a risk to patients sensitive to mites.

A lack of compliance with the measures to control mites could have played a part in the negative results, but only in one study ${ }^{25}$ was adherence to protocols evaluated. Adherence to protocols was higher and the amount of mites patients were exposed to was lower in the group that received computer assisted instruction when compared with the group that received conventional instruction. Those subjects who received computer assisted instruction implemented significantly more avoidance measures and had fewer symptoms. 
Our meta-analysis did not seem to lack power. The point estimates were close to zero and the confidence interval was narrow for morning peak flow rate, the most commonly used outcome measure, which is related to the severity of the asthma and is sensitive to change. This does not suggest we missed any worthwhile effect. If the difference in morning peak flow is transformed into the most commonly used unit of measurement $(\mathrm{l} / \mathrm{min})$ with a standard deviation of $100 \mathrm{l} / \mathrm{min}$ (in accordance with fig 3), the difference in peak flow between treatment and control groups is only $-3 \mathrm{l} / \mathrm{min}(-25 \mathrm{l} / \mathrm{min}$ to $19 \mathrm{l} / \mathrm{min})$.

\section{Potential sources of bias}

Potential sources of bias must be considered. Randomisation methods were not reported except in one study. In several studies researchers or patients were not blinded, and most studies were small. These factors all tend to be associated with an overestimation of reported treatment effects. Further, reporting was variable (for example, one study reported only that there were no significant changes in symptom scores, drug requirements, or peak flow rates ${ }^{13}$ ). It is generally safe to assume that unreported data do not favour the intervention. On a few occasions it was necessary to correct the original data; for example, in one study we could not confirm a reported significant effect on mite allergen level. $^{12}$

We tried to avoid bias while extracting data (for example, by making blinded decisions when several options were available). On a few occasions, however, we had to use data that favoured the experimental interventions (appendix 1 on the website). Finally, the trials we excluded did not have positive results (appendix 2 on the website) and we therefore believe we have not favoured the null hypothesis of no treatment effect in our meta-analysis.

There is a possibility that the results of effective interventions have been diluted by ineffective ones or by trial designs that were insufficiently rigorous. The length of follow up varied but was completely unrelated to the effect of treatment (for example, the three trials with 6-12 months of follow up showed a difference of 0.01 ( -0.36 to 0.38 ) in morning peak flow). This is to be expected since an effect on the reduction of allergens should be noticeable in the short term because mite allergen causes a Type I hypersensitivity reaction. There may be a subset of patients who are highly sensitive to mites who would benefit from mite eradication. It would, however, be difficult to detect such patients and it seems more reasonable to assess the effects of mite eradication on all patients with asthma whose skin prick tests indicate a sensitivity to mites.

\section{Conclusion}

Current chemical and physical methods for eradicating mites or reducing exposure to mites seem to be ineffective and cannot be recommended as prophylactic treatment for asthma patients who are sensitive to mites. It is doubtful whether conducting further studies similar to the ones in our meta-analysis would be worthwhile. In particular, several of the trials had used extensive mite eradication and avoidance schemes. We suggest that future studies should be much larger and more rigorous than those analysed here and should
Key messages

- Current chemical and physical methods aimed at reducing exposure to allergens from house dust mites seem to be ineffective; these methods cannot be recommended as prophylactic treatment for asthma patients who are sensitive to mites

- It is unlikely that a worthwhile effect has been overlooked in this meta-analysis since the confidence interval for the peak expiratory flow rate was quite narrow

- Future studies should be much larger and more rigorous than those in this meta-analysis and should evaluate other methods of mite control than those used to date

use methods to control or eradicate mites other than those used so far. Our review is also published in The Cochrane Library ${ }^{29}$ where it will be updated when results from additional studies become available.

We would like to thank Professor Paul W Jones, Mr Steve Milan, Ms Anna Bara, and Dr Jane Dennis, of the Cochrane Airways Group; Professor Vinod K Diwan and Professor Martin Bland for helpful support; and Dr Leonardo Antonicelli for providing additional data.

Contributors: $\mathrm{CH}$ wrote the draft protocol for the meta-analysis. $\mathrm{CH}$ and $\mathrm{MB}$ selected trials for inclusion. Trials were reviewed by all authors. Quality assessment of the trials was primarily done by $\mathrm{CH}$, outcome data were extracted primarily by PCG (but discussed in detail with all authors), CH drafted the first manuscript for the Cochrane Library, PCG drafted the manuscript for the journal article. All authors are guarantors for the article, and PCG is guarantor for the statistical calculations.

Funding: Nordic Council of Ministers; Hovedstadens Sygehusfaellesskab, Rigshospitalet, Denmark; Sygekassernes Helsefond, Denmark; the Swedish Heart Lung Foundation (grant 54506).

Conflict of interest: None.

1 Custovic A, Simpson A, Chapman MD, Woodcock A. Allergen avoidance in the treatment of asthma and atopic disorders. Thorax 1998;53:63-72.

2 Review manager:version 3.1 for Windows. Oxford: Cochrane Collaboration, 1998. (Available from: www.cochrane.dk.)

3 Bland JM, Altman DG. Measurement error proportional to the mean. BMJ 1996;313:106.

4 Gøtzsche PC. Bias in double-blind trials. Dan Med Bull 1990;37:329-36.

5 Antonicelli L, Bilo MB, Pucci S, Schou C, Bonifazi F. Efficacy of an air-cleaning device equipped with a high efficiency particulate air filter in house dust mite respiratory allergy. Allergy 1991;46:594-600.

6 Burr ML, St Leger AS, Neale E. Anti-mite measurements in mite-sensitive adult asthma: a controlled trial. Lancet 1976;1:333-5.

7 Burr ML, Dean BV, Merrett TG, Neale E, St Leger AS, Verrier-Jones ER. Effects of anti-mite measures on children with mite-sensitive asthma: a controlled trial. Thorax 1980;35:506-12.

8 Burr ML, Neale E, Dean BV, Verrier-Jones ER. Effect of a change to mitefree bedding on children with mite-sensitive asthma: a controlled trial. Thorax 1980;35:513-4.

9 Dietemann A, Bessot JC, Hoyet C, Ott M, Verot A, Pauli G. A double-blind, placebo controlled trial of solidified benzyl benzoate applied in dwellings of asthmatic patients sensitive to mites: clinical efficacy and effect on mite allergens. J Allergy Clin Immunol 1993;91:738-46.

10 Dorward AJ, Colloff MJ, MacKay NS, McSharry C, Thomson NC. Effect of house dust mite avoidance measures on adult atopic asthma. Thorax 1988;43:98-102.

11 Ehnert B, Lau-Schadendorf S, Weber A, Buettner P, Schou C, Wahn U. Reducing domestic exposure to dust mite allergen reduces bronchial hyperreactivity in sensitive children with asthma. J Allergy Clin Immunol 1992;90:135-8.

12 Geller-Bernstein C, Pibourdin JM, Dornelas A, Fondarai J. Efficacy of the acaricide: Acardust for the prevention of asthma and rhinitis due to dust mite allergy in children. Allergie et Immunologie 1995;27:147-54.

13 Gillies DRN, Littlewood JM, Sarsfield JK. Controlled trial of house dust mite avoidance in children with mild to moderate asthma. Clin Allergy 1987; $17: 105-11$

14 Marks GB, Tovey ER, Green W, Shearer M, Salome CM, Woolcock AJ House dust mite allergen avoidance: a randomised controlled trial of surface chemical treatment and encasement of bedding. Clin Exp Allergy 1994;24:1078-83 
15 Mitchell EA, Elliott RB. Controlled trial of an electrostatic precipitator in childhood asthma. Lancet 1980;2:559-61.

16 Reiser J, Ingram D, Mitchell EB, Warner JO. House dust mite allergen levels and an anti-mite mattress spray (natamycin) in the treatment of childhood asthma. Clin Exp Allergy 1990;20:561-7.

17 Sette L, Comis A, Marcucci F, Sensi L, Piacentini GL, Boner AL. Benzylbenzoate foam: effects on mite allergens in mattress, serum and nasal secretory IgE to Dermatophagoides pteronyssinus, and bronchial hyperreactivity in children with allergic asthma. Pediatr Pulmonol 1994;18:21827.

18 Verrall B, Muir DCF, Wilson WM, Milner R, Johnston M, Dolovitch J. Laminar flow air cleaner bed attachment: a controlled trial. Ann Allergy 1988;61:117-22

19 Walshaw MJ, Evans CC. Allergen avoidance in house dust mite sensitive adult asthma. O J Med 1986;58:199-215

20 Warburton CJ, Niven RMcL, Pickering CAC, Fletcher AM, Hepworth J, Francis HC. Domiciliary air filtration units, symptoms and lung function in atopic asthmatics. Respir Med 1994;88:771-6.

21 Warner JA, Marchant JL, Warner JO. Double blind trial of ionisers in children with asthma sensitive to the house dust mite. Thorax 1993;48:330-3.

22 Zwemer RJ, Karibo J. Use of laminar control device as adjunct to standard environmental control measures in symptomatic asthmatic children. Ann Allergy 1973;31:284-90.

23 Carswell F, Birmingham K, Oliver J, Crewes A, Weeks J. The respiratory effects of reduction of mite allergen in the bedrooms of asthmatic children: a double-blind controlled trial. Clin Exp Allergy 1996;26:386-96.

24 Van der Heide S, Kaufmann HF, Dubois AEJ, de Monchy JGR. Allergenavoidance measures in homes of house-dust-mite-allergic asthmatic patients: effects of acaricides and mattress encasings. Allergy 1997;52:921-7.

25 Huss K, Squire EN, Carpenter GB, Smith LJ, Huss RW, Salata K, et al. Effective education of adults with asthma who are allergic to dust mites. $J$ Allergy Clin Immunol 1992;89:836-43.

26 Maesen FPV, Sluysmans FG, Brombacher PJ, Smeets JJ. Ervaringen met het gebruik van luchtfiltratieapparatuur in de woonruimten van voor huisstof overgevoelige atopische patienten. Acta Tuberc Pneumol Belg $1977 \cdot 68 \cdot 133-47$

27 Ihre E, Axelsson IGK, Zetterström O. Late asthmatic reactions and bronchial variability after challenge with low doses of allergen. Clin Allergy 1988; 18:557-67.

28 Ihre E, Zetterstrom O. Increase in non-specific bronchial responsiveness after repeated inhalation of low doses of allergen. Clin Exp Allergy 1993;23:298-305.

29 Hammarquist C, Burr ML, Gøtzsche PC. House dust mite control measures in the management of asthma. In: The Cochrane Library, Issue 3. Oxford: Update Software, 1998.

(Accepted 28 July 1998)

\section{Science commentary: Hypersensitivity revisited}

Science commentary
When someone who is allergic to house dust mites starts wheezing they are experiencing a type I hypersensitivity reaction. Type I reactions occur rapidly and are mediated by $\mathrm{IgE}$ antibodies (to the allergen) which bind strongly to the surface of mast cells in the skin. The synthesis of IgE antibodies is triggered by $\mathrm{T}$ helper cells (Th 2 cells) which produce a number of inflammatory cytokines in the process. The most important cytokine in these type I responses is interleukin 4.

When the IgE antibodies bind to mast cells they break open and release histamine which causes the clinical symptoms. The clinical response usually stops when the allergen is removed or when the inflammatory response is dampened down by antihistamine drugs or anti-inflammatory drugs. Other type I hyper- sensitivity reactions include allergic rhinitis, eczema, urticaria, and systemic anaphylaxis.

Type II and type III hypersensitivity reactions are mediated by IgG antibodies. These set off the complement cascade which induces phagocytosis of the allergens. Common examples of these hypersensitivity reactions include reactions to drugs and serum sickness. Type II reactions are directed against antigens on the cell surface; type III reactions are directed against soluble antigens.

Type IV hypersensitivity reactions are mediated by $\mathrm{T}$ cells, and tissue damage is caused by macrophages and cytotoxic $\mathrm{T}$ cells. Contact dermatitis is a clinical example of a type IV hypersensitivity reaction.

Abi Berger Science editor, BMJ

\section{A memorable consultant Perils of opera}

"I'm afraid I think that is a carcinoma of the larynx," the ear, nose, and throat consultant leaned over the radiologist to point to an opacity on the barium swallow.

"I have to agree," said the radiologist, taking the film from the screen to study it more closely.

My heart seemed to run south like a nervous squirrel as the implications sank in. Three weeks earlier I had become aware of a vague discomfort in the throat followed some days later, to the evident relief of my colleagues, by an increasing loss of voice.

The ear, nose, and throat consultant put a reassuring hand on my shoulder. "I'll refer you to the top man in this field in London immediately."

A fortnight later I was shown into the Great Man's office. He was seated behind a large clear desk; a small, gnome like man with twinkling eyes. He gestured towards a chair in front of me.

"Sit down young man and tell me the story."

After I had given him what I hoped was the ideal patient history in a hoarse crackly voice, he stood up and came round the desk.

"Let's have a look at you." After a few minutes of gentle probing and the use of light and mirror, he started back round the desk. He stopped at the side tapping his cheek reflectively with his pen.
"Hmm," he said, "I should think your favourite opera is either La Bohème or Faust, though you may perhaps prefer Bellini." I blinked as he resumed his seat. How could he possibly know of my love for La Bohème and Faust or indeed for Bellini. Not for me the weighty paragraphs of Wagner.

"And your favourite singer is probably Bjorling or Gigli or even this new chap Pavarotti." the Great Man went on.

I nodded dumbly, "Bohème and Bjorling," I croaked.

He smiled, "And you always try to join him in that top C in the first act usually while you're in your car."

Balbao viewing the Pacific must have had less of "wild surmise" than I. How on earth could this magical man know this? He answered my look. "Because all you have is a loose left vocal chord which you have abused trying to reach high notes with no training. Speak as little as possible for the next month and all will be well, but please," he paused, "Please don't sing in the car."

There was a sad sequel. Some three months later this marvellous man, Freddie Capps, died quite suddenly. But I was able by then to tell the story in a restored, but alas still baritonal, voice. Bjorling remained unchallenged.

James Wright, retired consultant physician, Yelverton, Devon 